\title{
AMENDMENTS
}

\section{Author Correction: A SARS-like cluster of circulating bat coronaviruses shows potential for human emergence}

Vineet D. Menachery, Boyd L. Yount Jr, Kari Debbink, Sudhakar Agnihothram, Lisa E. Gralinski, Jessica A. Plante, Rachel L. Graham, Trevor Scobey, Xing-Yi Ge, Eric F. Donaldson, Scott H. Randell, Antonio Lanzavecchia, Wayne A. Marasco, Zhengli-Li Shi and Ralph S. Baric

Correction to: Nature Medicine https://doi.org/10.1038/nm.3985, published online 9 November 2015.

In the version of this article initially published, the sequence of the mouse adapted SHC015-MA15 virus had not been deposited in GenBank. The sequence has now been deposited in GenBank under accession number MT308984.

(C) The Author(s), under exclusive licence to Springer Nature America, Inc. 2020

Published online: 22 May 2020

https://doi.org/10.1038/s41591-020-0924-2

(c) The Author(s), under exclusive licence to Springer Nature America, Inc. 2020

\section{Author Correction: Caring for patients with cancer in the COVID-19 era}

Joris van de Haar, Louisa R. Hoes, Charlotte E. Coles, Kenneth Seamon, Stefan Fröhling, Dirk Jäger, Franco Valenza, Filippo de Braud, Luigi De Petris, Jonas Bergh, Ingemar Ernberg, Benjamin Besse, Fabrice Barlesi, Elena Garralda, Alejandro Piris-Giménez, Michael Baumann, Giovanni Apolone, Jean Charles Soria, Josep Tabernero (D), Carlos Caldas (D) and Emile E. Voest (10)

Correction to: Nature Medicine https://doi.org/10.1038/s41591-020-0874-8, published online 16 April 2020.

In the version of this article initially published, the CCE Contributors Appendix in the Supplementary Note was missing the name 'Paul D.P. Pharoah. The correct text should read as follows: “...and Paul D.P. Pharoah, of the Cancer Research UK Cancer Centre...”. An updated Supplementary Note is now provided.

Published online: 3 June 2020

https://doi.org/10.1038/s41591-020-0948-7

๑) Springer Nature America, Inc. 2020 